\title{
THE DEVELOPMENT OF SECOND LANGUAGE IN TWINS VERSUS SINGLES
}

\author{
Iram Shahzadi \\ M. Phil Scholar, Department of English, University of Gujrat \\ irsha.aj@gmail.com \\ Behzad Anwar \\ Assistant Professor, Department of English, University of Gujrat \\ behzad.anwar@uog.edu.pk \\ Shukraan Bin Umer \\ BS Scholar, Department of English, University of Gujrat
}

\begin{abstract}
This study focuses on the development of language learning of twins versus singles at their early school age (grade 3 to 8) in district Gujrat. The data has been collected from 9 participants who were divided into three groups $(A, B$ and $C)$ by the researchers with respect to their age. For data collection, the researchers gave the task of picture description, sentence making and passage reading to the participants of each group, both in pre-test and post-test accordingly. As the data was collected through recordings, the researcher calculated the results of all the groups manually. For the analysis of the study, SPSS (independent t-test and two-way ANOVA) software was used. Moreover, the researchers applied the socio-cultural theory of Vygotsky (1978) to explain the difference in the zone of proximal development among twins and singletons. The results showed that there is a difference in the learning of twins and singletons at every age scale. Even though the difference is present in every individual but there are some inner and outer factors as well that become the cause of differences in the learning of twins and singletons.
\end{abstract}

Keywords: Second language, Twins, Singles, Pre-test, Post-test.

\section{INTRODUCTION}

Language is an important and habitual phenomenon. The language that is spoken at homes is called first language and it is easy for the learner to learn a first language as compared to a second language. As English is considered a second language mostly and is known as lingua franca, it is important to learn it. But learning a second language, English or any other, is not an easy task. As language is a habitual process, it needs time and a proper environment. The current study is about the second language development with reference to the differences in the learning of second language of twins versus singletons. It is a well acknowledged fact that there are some differences in the learning of languages (first or second) but the difference in the learning of language between singles and twins is also very important. There are many factors that affect the language learning including social background, age, gender and parents or family members. Garitte, Almodover, Benjamin, and Canhao (2019) studied the difference between same and different sex twins while applying the theory of zone of proximal development.

Monozygotic twins have same genetic makeup and both of the infants share the same placenta while dizygotic twins have different genetic makeup and they have separate placenta. Magford (1988) studied the language delay in twins. Monozygotic twins are also called identical twins and dizygotic twins are known as fraternal twins or non-identical twins. Fraternal twins can be of the same sex or different sex.

\section{Theoretical Background}

Scaffolding is a term that was introduced by Wood, Bruner and Ross (1976) while working on the conversations between parents and children. Scaffolding is somehow related to the word 'help or treatment' but this type of help is not physical rather psychological and emotional. Scaffolding (treatment) acts as assistance or temporary assistance provided by teacher or instructor to learner. It helps the learners to become able to solve the problems themselves. In other words, scaffolding 
increases the learner's autonomy. Mariani (1997) elaborated the whole concept of zone of proximal development with the help of a diagram. The following diagram highlights the four zones of learning or four types of learning environments, low support>high challenge, low support>low challenge, high support>high challenge.

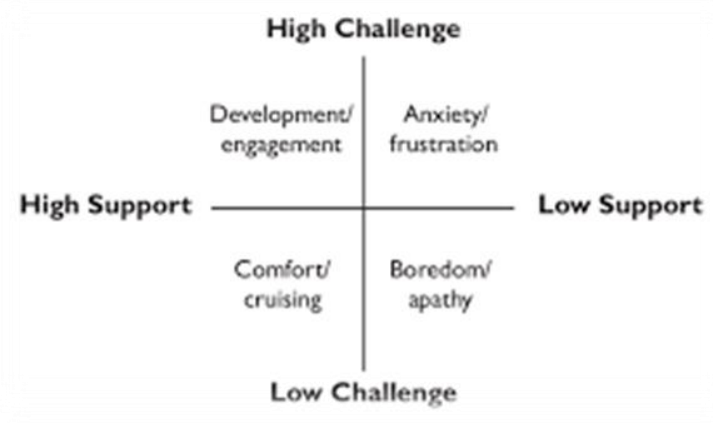

Figure-1

It is expected that a high challenging environment with high support leads towards the extraordinary learning of the learners (Dennen \& Burner, 2008). Gibbons (2002) gave almost full explanation of scaffolding in his book Scaffolding and Learning. If the scaffolding or support is high the results are more likely to be positive. If the support is kept high, then the learner would feel comfortable while dealing with even a difficult task otherwise the new challenges may confuse him or her and lead to the anxiety and boredom. For second language learners, it is the duty of instructor to give clues and hints. For example, a teacher can give some starting words like "firstly, second term, in the other words or on the other hand" in sentence making.

\section{Research Question}

1. How do twins differ in second language development from singletons at early school age?

\section{Hypothesis}

- There is significant effect of gender and age on the learning of learners (twins and singletons).

- There is no significant effect of gender and age on the learning of learners (twins and singletons).

- There is significant difference in the language learning of twins versus singletons.

- There is no significant difference in the language learning of twins versus singletons.

\section{REVIEW OF LITERATURE}

An early study about the twins versus singletons by Day (1932) indicates a comparison between language skills of twins and singletons of the same age. The variables used by the researchers were age, parents, sex and parental occupations. The sample of 50 utterances was recorded by taking the test from children and the home observation was also noted. According to the results, twins at early two years have more language delay but in the later years they hit the average language learning speed of singletons.

Prediction of reading disability was studied by Jhontson, Prior, and Hay (1984) to check the intelligence and reading ability. The sample of 26 twin boys was analyzed while considering the other factors like social background, language learning and social characteristics. The findings indicated that the male twins have more risk of reading disability as compared to the female twins and language disability might be the result of reading disability. L1 plays an important role in the learning of L2. A study was conducted for analyzing the role of first language during second language learning by following Vygotsky's theory. The findings showed that there is a significant relationship between L1 and L2. The inner functions of first language help in the learning of second language.

A twin study in which the influence of genetics on reading and spelling ability was carried out by Stevenson, Graham, Fredman, and Mcloughli (1987). The findings highlighted that the 
genetic factors affected moderately at the age of 13 in reading but spelling ability of the children was strongly affected by the genetic factors. The results showed that there is a strong relation between genetics and spelling ability and disability among monozygotic and dizygotic twins.

Bishops (1998) studied the twin language (a risk factor for language impairment) in which he took two types of samples, one consisted of 94 pairs of twins from ages 7 to 13, recruited by school language $(G)$ and other type of sample consisted of 82 twin pairs for genetic study (L). The researcher also gathered questionnaires from their parents to validate the data. The findings of study revealed that the pairs who used a secret language for communication with each other committed errors than that pairs who did not use a private language for communication. The mean of nonverbal IQ level of twins who used a private language and those who did not, was the same. The results strongly suggested that the use of private language effects negatively on the second language learning of twins.

Moreover, Harlaar, Thomas, Dale, and Plomin (2008) worked on the preschool language abilities affecting the later reading achievements. The purpose of their study was to know the actual relationship between language ability and later reading achievement. They took the sample of 7,179 twin pairs from ages 3 to 4 and 7 to 9 . Furthermore, parental reports and teacher assessments were also noted to check the co-relation. The results indicated that shared environment affects the later learning of language and reading ability. Genetics also has an influence on the phenotypical relation of language ability and reading achievement because the effect of environment is significant in their correlation. At the end, they concluded that early language has effects on later achievements because of shared environment and genetics influences as well.

Dale, Harlaar, Haworth, and Plomin (2010) studied the twin's second language acquisition in comparison to first language acquisition, in which they discussed four skills (reading, writing, listening, and speaking) by designing an international curriculum while using the sample of 604 children of 14 years age. The result of the study highlighted that genetic analysis shows high difference in language development but influence of environment in comparison to both domains of L1 and L2 language is very low. Furthermore, the past studies were conducted on the basis of parental response or on the basis of the academic results in different subjects but in this research the researchers investigated the differences in second language learning in twins versus singletons. It is considered that twins used a special type of secret language to communicate with each other which is incomprehensible for others. This secret language phenomenon is called cryptophasia (firstly used by the Zazzo in 1960, 1978).

The zone of proximal development in Vygotsky's analysis of learning and instructions was studied by Kozuline, Gindis, Ageyev, and Miller (2003) to answer different questions about Vygotsky's theory of zone of proximal development. According to Kozuline et al., (2003) Vygotsky's used a term of imitation in different senses. He did not mean it as a copy of action. "Everything that the child cannot do independently, but which he can taught or which he can do with the cooperation or with the help of leading questions" (1934/1998b, p. 202). Moreover, they discussed three aspects of zone of proximal development; generality assumption (general for all subjects learning), assistance assumption (learning is more dependent on others) and potential assumption (learner's ability to learn something).

Thorpe (2006) investigated the twin's language learning and he concluded that language delay is high in twins as compared to the singletons. He found that the language delay is not just a genetic problem but external factors such as environment also play an important role in causing language delay. His study is actually based on the previous studies' data on related topics. A study by Byrne et.al (2007) found that the effect of environment on the cognition was negative but genetics positively influenced to increase the cognition variable with the age getting older.

\section{METHODOLOGY}

This study is experimental in nature and SPSS has been used to analyze the data. The researchers divided the groups according to their age. The sample of the study consists of three participants of twins and three participants of singletons with same age in each group. The total population of participants is nine (9), age 8 to 10,10 to 12 and 12 to 14 of grades 3,6 and 8 .

The researchers also used socio-cultural theory of Vygotsky to explain the zone of proximal development. For the analysis of pre-test and post-tests, SPSS software has been used. SPSS stands 
for social package for social science and is used to analyze the quantitative data. The researchers manually calculated the utterances in sentences and then put the results in software for independent $t-$ test and then Two-way ANOVA test is used to check the effects of dependents values on independent values.

\section{Data Collection}

There are three phases of data collection and the researchers collected the data from twins and singleton ranging the age from 7 to 10. In the second phase, the examiner collected the data from participant's age 10 to 12 and in the third phase, from the participants of age 12 to 14 .

For data collection, the examiner provided a passage from the course book (in second language related to their age) to participants to read it in the pre-test with some hints in every activity. The participants were asked to read it word by word and the examiner recorded the utterances to check the reading skills in second language. The researchers recorded the utterances from twins as well as from the singletons of each group individually when they were reading the paragraphs. The length of the sentences and number of utterances were calculated and transcribed by the researchers. Then, after some time the examiner provided them a picture to describe it in a few sentences while recording it. Then for two days the researcher did not take test and just taught them by providing the proper learning environment to each group. After two days, the examiner again took the picture description from the participants of same picture from their text books to check their potential development as described by Vygotsky's theory (level of language learning).

To make the participants feel easy, the researchers arranged different activities. The reason to select the sample of different ages is to examine the dependency of one co-twin on another so that the researchers could make it sure whether dependency of twins increases or decreases with the passage of time or not. Pretest and posttest were used as tools for data collection from the participants to assess the zone of proximal development. While detecting the pretest the researchers provided the participants with different clues and hints in the second language (the clues and hints were based on some words or half sentences to complete them which helped the participant to get the idea) and the hints were reduced to check the progress with the proceeding phase. SPSS software is used for the reliability of results to check the effect of gender during pretest and posttest.

\section{DATA ANALYSIS AND DISCUSSION}

Mcmahon and Dodd (1997) discussed the comparison between the expressive communication skills among twins, triplets and singletons on the level of mean length of utterances, conversational acts, and phoneme repertoire. Different phonological processes were noted while using the ANOVA and MANOVA tests to calculate the difference among multiple birth children. The mean length of utterances (MLU) has been calculated as the sum of utterances divided by the total number of words in a paragraph as Cazden's (1965) calculated.

Rezaee and Azizi (2012) worked on the role of proximal development. The results revealed that supportive and collaborative environment has a good impact on high school students in Iran. It was concluded that students under ZPD error of correction have better and deeper learning as compared to the students without the ZPD environment. By following this method, the researchers collected the data. The table given below shows the average scores of the participants in sentence making. Besides, the mean of utterances while reading the passage and the use of vocabulary in second language while describing the pictures of both pretest and posttest are also mentioned. During the second session of data collection, the researchers also took the pretest and posttest from the participants according to their level from their course books.

Table No. 1. Group A scores

\begin{tabular}{lcclccc}
\hline Participants & \multicolumn{2}{l}{ Mean of Pretest Scores } & \multicolumn{4}{l}{ Mean of Posttest Scores } \\
\hline & $\begin{array}{l}\text { Paragraph } \\
\text { reading }\end{array}$ & $\begin{array}{l}\text { Sentence } \\
\text { making }\end{array}$ & $\begin{array}{l}\text { Picture } \\
\text { description } \\
\text { (vocabulary) }\end{array}$ & $\begin{array}{l}\text { Paragraph } \\
\text { reading }\end{array}$ & $\begin{array}{l}\text { Sentence } \\
\text { making }\end{array}$ & $\begin{array}{l}\text { Picture } \\
\text { description }\end{array}$ \\
Co-twin N & 0.9625 & 0.4 & 0.60 & 0.9875 & 0.6 & 0.80 \\
Co-twin U & 0.9875 & 0.6 & 0.75 & 1 & 1 & 0.95 \\
Single A & 0.9375 & 0.5 & 0.65 & 0.9875 & 0.7 & 0.85 \\
\hline
\end{tabular}


The above table shows the difference of average scores that the singleton (A) and both of the twin members got in pretest and then after treatment in posttest. The sequence of three phases includes paragraph reading (from their course book), sentence making with hints in pretest and without hints in posttest. At the end, in picture description, the number of words in second language (English) which they have used while describing the picture were measured.

\section{Table No. 2. Group A Total Score}

\begin{tabular}{ccc}
\hline Participants & Total of all pretests & Total of all posttest \\
\hline Co-twin b & 1.9625 & 2.38 \\
Co-twin a & 2.3375 & 2.95 \\
Singleton c & 2.0875 & 2.53
\end{tabular}

The difference of the individual scores of the pretest and posttest of the participants shows the role of scaffolding (a treatment before posttest) in learning the second language. Moreover, the difference among the participant's scores shows the difference in the zone of proximal level of the children related to the same social background; of same grade in same school (same educational environment) and same age, having same first language and studying English as a second language.

Table No. 3. Group B scores

\begin{tabular}{lcccccc}
\hline Participants & & \multicolumn{2}{c}{ Pre-test score's mean } & \multicolumn{3}{c}{ Posttest score's mean } \\
\hline & $\begin{array}{l}\text { Passage } \\
\text { reading }\end{array}$ & $\begin{array}{c}\text { Picture } \\
\text { description }\end{array}$ & $\begin{array}{l}\text { Sentence } \\
\text { making }\end{array}$ & $\begin{array}{l}\text { Passage } \\
\text { reading }\end{array}$ & $\begin{array}{l}\text { Picture } \\
\text { description }\end{array}$ & $\begin{array}{c}\text { Sentence } \\
\text { making }\end{array}$ \\
$\begin{array}{c}\text { Co-twin } \\
\text { (girl) }\end{array}$ & 0.7766 & 0.19 & 0.40 & 0.9514 & 0.3 & 0.466 \\
$\begin{array}{l}\text { Co-twin } \\
\text { (boy) }\end{array}$ & 0.9805 & 0.22 & 0.46 & 1 & 0.40 & 1 \\
$\begin{array}{l}\text { Singleton } \\
\text { (girl) }\end{array}$ & 0.9514 & 0.24 & 0.40 & 1 & 0.44 & 0.866 \\
\hline
\end{tabular}

The above table no. 3 shows the difference in the scores of the participants of group B, which they have got by passage reading. The mean or average of the reading is measured by dividing the number of utterances with the morphemes of the words in the whole passage. The difference in the average scores of the girl (co-twin) is less not only in the pretest but also in posttest and less from other participants too.

Table No. 4. Group B Total Score

\begin{tabular}{ccc}
\hline Participants & Total of pretests & Total of posttests \\
\hline Co-twin (a,girl) & 1.36 & 1.71 \\
Co-twin (b,boy) & 1.66 & 2.40 \\
Singletons $\odot$ & 1.59 & 2.30
\end{tabular}

On the third phase of data collection, the researcher visited the home of participants of age ranging from 12 to 14 , of grade 8 , to check the difference of learning second language among them. Furthermore, the examiner also played a role in child oriented activities to make them unconscious of the observation and for the sake of engagement. On the first day of visit, the examiner asked the participants to read a passage as in the first phase of data collection in an isolated room. The participants read the paragraph one by one.

\begin{tabular}{llccccc}
\hline Participants & \multicolumn{4}{c}{ Pretest scores } & \multicolumn{3}{c}{ Post-test score } \\
\hline & Passage & Sentence & Picture & Passage & Sentence & Picture \\
& reading & making & description & reading & making & description \\
$\begin{array}{l}\text { Co-twin } \\
\text { (boy1) }\end{array}$ & 0.98 & 3.8 & 0.28 & 0.99 & 8.0 & 0.63 \\
\hline
\end{tabular}




\begin{tabular}{lcccccc}
\hline $\begin{array}{l}\text { Co-twin } \\
\text { (Boy2) }\end{array}$ & 0.96 & 3 & 0.27 & 0.99 & 7.7 & 0.38 \\
Singleton & 0.99 & 1.8 & 0.72 & 1 & 8.8 & 0.92 \\
\hline
\end{tabular}

Table No. 5. Group C scores

The table 5 shows the difference between the pretest and the posttest in passage reading, sentence making and picture description. The table shows that there is no significant difference in the passage reading of the participants. They got approximately similar scores in pretest and posttest. But in the case of the sentence making, pretest of the twins shows similar scores but the singleton's performance is not good. On the other hand, in the case of picture description, singleton got more scores than twins which show the mean length of utterances. Last three columns indicate the progress of the participants as compared to the pretest. But one of the participants, the co-twin did not show good performance as the other two did.

Table No. 6. Total scores of group C

\begin{tabular}{lcc}
\hline Participants & Total points of pretest & Total points of posttest \\
\hline Co-twin (boy 1) & 5.06 & 9.62 \\
Co-twin (boy 2) & 4.23 & 9.07 \\
Singleton & 3.51 & 10.7
\end{tabular}

The above table highlights the difference of total scores (including passage reading, sentence making and picture description) of both pretest and posttest. The scores of the pretest showed the participants' prior knowledge and the average scores of the posttest highlighted what the participants could do with the help of scaffolding (treatment) which was in the form of instructions and clues. The pretest was provided with the clues and hints but in the case of the posttest the clues and hints were excluded.

Table No. 7. Group Statistics

\begin{tabular}{|c|c|c|c|c|c|}
\hline & $\begin{array}{l}\text { Participants } \\
\text { group }\end{array}$ & $\mathbf{N}$ & Mean & Std. Deviation & $\begin{array}{l}\text { Std. } \\
\text { Error } \\
\text { Mean } \\
\end{array}$ \\
\hline \multirow{2}{*}{ scores before scaffolding } & 1 (twins) & 6 & 2.7667 & 1.51298 & .61767 \\
\hline & 2 (singletons) & 3 & 2.3700 & 1.02621 & .59248 \\
\hline \multirow{2}{*}{ scores after scaffolding } & 1 (twins) & 6 & 4.6967 & 3.62441 & 1.47966 \\
\hline & 2 (singletons) & 3 & 5.1967 & 4.76678 & 2.75210 \\
\hline
\end{tabular}

The table 7 represents the independent sample T-test which is used for the comparison of mean of two unrelated groups with the same dependent variables. The mean difference of twins versus singletons can be seen in second box of mean. The mean of pretest of twins is 2.766 and of singles is about to 2.37 which indicated the difference of 0.396 . But, in the case of posttest, the mean of twins is 4.69 after the treatment and the singletons managed the mean of 5.19 which indicates that the mean result of singles is higher than the twin's mean result.

As the researchers used SPSS for the analysis of the data to check the effect of gender and age on the scores and authenticity of data, the following table shows the comparison of the mean and standard deviation of both twins and singles as well as pretest and posttest of all the participants collectively. Two sub-columns of the test are F and Sig. If the value of the Sig. is more than 0.05 then read out the values of first row otherwise read out the second row's value.

Here, the first Sig. value is 0.274 which is greater than 0.05 , so the researchers must focus on the top row's values. The greater value indicates that the two conditions are changed by chance but the difference between them is approximately 0.699 before scaffolding (pretest). On the other hand, the difference value of scores after scaffolding (posttest) is also greater than the pretest which indicates the results difference of both conditions (twin and singletons). As the researcher must focus on the top row, so the Sig 2-tailed value is more than 0.05. It can be concluded that the null hypothesis, "There is no difference between the learning of singletons and twins" is rejected. So, the results show there are some significant differences between the achievement of twins and singletons. 
Table No. 8. Independent t-test

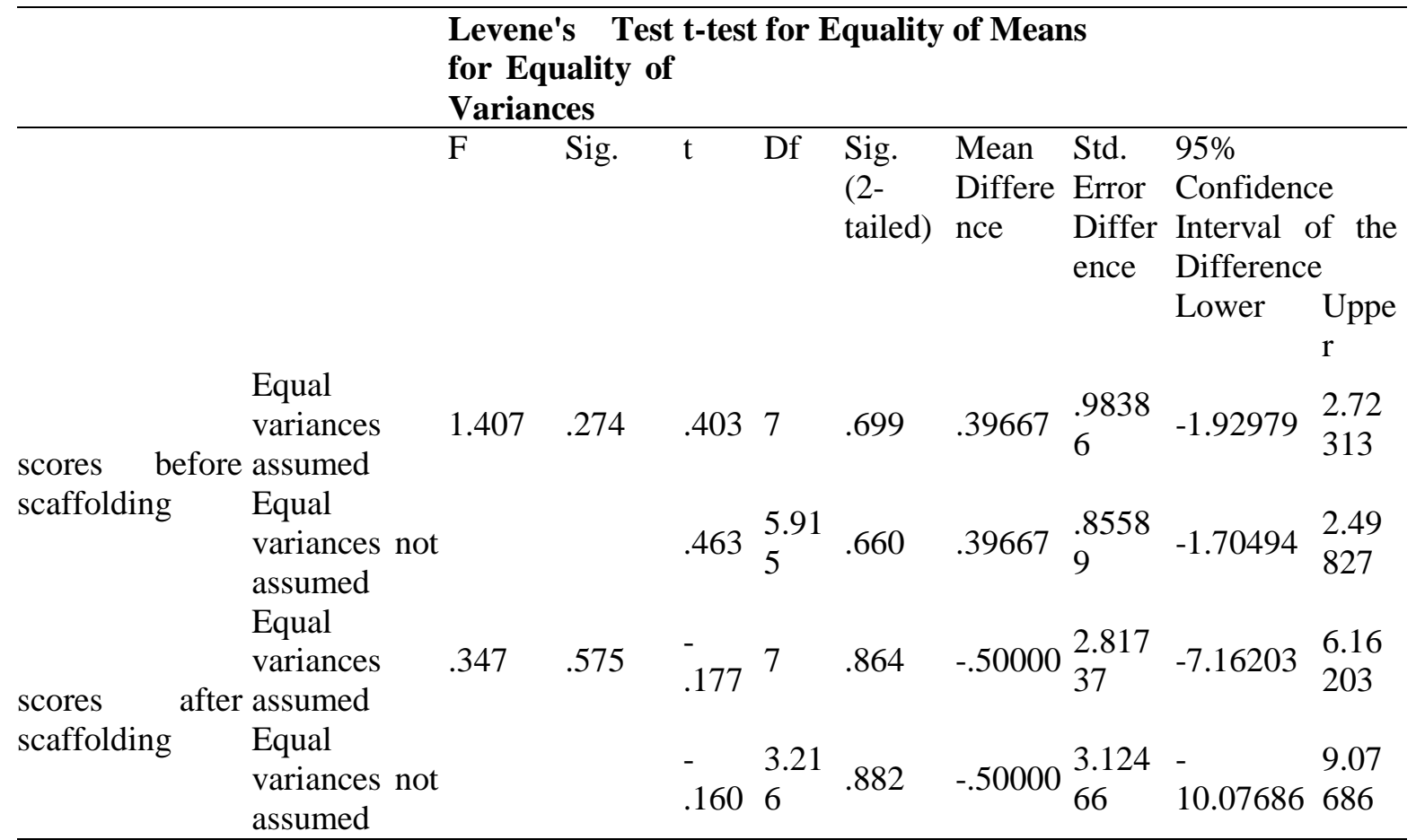

Confidence intervals are defined as the intervals linked to the confidence level about to $95 \%$ to assure that the results of unknown parameter would be approximately equal or near to the value of confidence interval's value. The difference in the twin and single's mean would be minimally equal to -1.92 to the 2.72 maximally before the treatment and after treatment would be among the values from -7.16 to 6.16 .

\section{The effect of gender and age}

Secondly, the researchers focused on the point if other social factors such as gender or age affect the development/learning of second language or not. It is a fact, if there is a significant difference in the pre-test results of twins and singles then after treatment or different type of support, there may not be significant difference in the scores of posttests. The researchers again entered the data in SPSS and applied two way Anova to check the effects of dependent variables on the independent variables. In this study, there are two factors; gender and age that are independent

Null hypothesis: There is no significant effect of gender and age on the scores of participants.

- Alternative hypothesis: There is a significant effect of gender and age on the scores of participants.

The following tables show the effect of gender and age on the second language development of twins and singletons.

Table No. 9. Effect of Gender and Age Before Scaffolding (pretest)

\begin{tabular}{llll}
\hline Between the subject factors & & Value Label & $\mathbf{N}$ \\
gender of the participants & 1 & Male & 3 \\
& 2 & Female & 6 \\
age of the participants & 1.00 & $8-10$ & 3 \\
& 2.00 & $10-12$ & 3 \\
& 3.00 & $12-14$ & 3 \\
\hline
\end{tabular}


The above table highlights the output containing two subjects or factors. There are two or three categories, for example, subject gender consists of two categories, male and female and same in the case of age, from 8 to 10,10 to 12 and 12 to 14 .

Table No. 10. Descriptive Statistic

\begin{tabular}{lllll}
\hline Gender of the Participants & Age of the Participants & Mean & Std. Deviation & N \\
\hline \multirow{3}{*}{ Male } & $10-12$ & 1.6600 & & 1 \\
& $12-14$ & 4.6450 & .58690 & 2 \\
& Total & 3.6500 & 1.77265 & 3 \\
\multirow{3}{*}{ Female } & $8-10$ & 2.1233 & .18877 & 3 \\
& $10-12$ & 1.4750 & .16263 & 2 \\
& $12-14$ & 3.5100 &. & 1 \\
\multirow{4}{*}{ Total } & Total & 2.1383 & .75629 & 6 \\
& $8-10$ & 2.1233 & .18877 & 3 \\
& $10-12$ & 1.5367 & .15695 & 3 \\
& $12-14$ & 4.2667 & .77565 & 3 \\
\hline
\end{tabular}

The above table shows the descriptive properties of scores which elaborated the mean, standard deviation and sig values of the participants. This table of descriptive statics analyzes the males' and female's description about the scores without any type of scaffolding. As Khaliliaqdam (2014) mentioned in his study about the zone of proximal development in second language learners while taking pretest and posttest, the researchers of this study also followed the same procedure of data collection and data analysis. In the second column of this table, the values indicated that the highest score's mean is 4.64 which belonged to a male participant. In the case of females, the highest score mean is 3.5 in pretest. So, the mean difference of males is greater than that of females.

Table No. 11. Test of Equality of Error Variances

\begin{tabular}{llll}
\hline F & df1 & df2 & Sig. \\
\hline 13.036 & 4 & 4 & .015
\end{tabular}

Tests the null hypothesis that the error variance of the dependent variable is equal across groups.

a. Design: Intercept + gender + age + gender * age

Above table shows the Leven's test of equality of error variance, one of the tests of two-way ANOVA that shows the variances in each condition are equal. The null hypothesis is that there is no significant effects of dependent variables on the scores of participants before the scaffolding. If the $p$ value of the test is greater than 0.05 then the null hypothesis has to be accepted otherwise if the $p$ value is less than 0.05 , then the null hypothesis has to be rejected. The value 0.015 is less than 0.05 , so the null hypothesis that there is no significance effect of dependent variables on the scores of participants is rejected and the alternative hypothesis that there is a significant effect of dependent variables on the scores of singletons and twins in pre-test is accepted.

Table No. 12. Subjects Effects

\begin{tabular}{|c|c|c|c|c|c|c|}
\hline Source & $\begin{array}{l}\text { Type I } \\
\text { of Squa }\end{array}$ & Df & Mean Square & $\mathbf{F}$ & Sig. & $\begin{array}{l}\text { Partial Eta } \\
\text { Squared }\end{array}$ \\
\hline Corrected Model & $13.273^{\mathrm{a}}$ & 4 & 3.318 & 30.017 & .003 & .968 \\
\hline Intercept & 55.611 & 1 & 55.611 & 503.075 & .000 & .992 \\
\hline Gender & .581 & 1 & .581 & 5.254 & .084 & .568 \\
\hline Age & 8.404 & 2 & 4.202 & 38.011 & .002 & .950 \\
\hline gender * age & .301 & 1 & .301 & 2.721 & .174 & .405 \\
\hline Error & .442 & 4 & .111 & & & \\
\hline Total & 76.547 & 9 & & & & \\
\hline Corrected Total & 13.715 & 8 & & & & \\
\hline
\end{tabular}

a. $\quad$ R Squared $=.968$ (Adjusted R Squared $=.936$ )

The above table shows six columns, related to specific category. But the point of discussion in table is Sig value and mean square. The test between the subjects can be checked out with the help 
of above table which informs the effects of all the factors individually. In first column of source and in the Sig. column values are important. The value of gender in Sig. is about 0.08 which is more than $\alpha$ value (0.05) and statistically not significant, so the null hypothesis that there is no effect of gender on the achievements of participants before the scaffolding is accepted. The same is in the case of age, the Sig. value is about 0.002 which is less than 0.05 and statistically significant, so the null hypothesis that there is no effect of age on the achievement of scores of participants is rejected. Third row is showing the interaction between both factors (gender and age). The Sig. value of interaction between the factors is 0.17 which is more than 0.05 , so it can be determined that there is no significant interaction between these two factors and sum of both factors has no effect on the achievements of the participants. The results show that there is a significant effect of gender difference after the scaffolding not before the scaffolding.

Table No. 13. Gender of the Participants

\begin{tabular}{lllll}
\hline Gender of the Participants & Mean & Std. Error & \multicolumn{2}{l}{ 95\% Confidence Interval } \\
& & & Lower Bound & Upper Bound \\
\hline Male & $3.153^{\mathrm{a}}$ & .204 & 2.587 & 3.718 \\
Female & 2.369 & .150 & 1.953 & 2.786 \\
\hline
\end{tabular}

The above table shows the mean, standard deviation and confidence interval of the pretest (hold before the instructions) on the basis of gender. The assumed confidence interval by the researchers is $95 \%$. The mean result of males out of the studied sample would be minimally about the range of 2.58 to maximally 3.71 . In the case of females, the confidence intervals are assuring the range from 1.95 to the 2.786 .

Table No. 14. Age of the Participants

\begin{tabular}{|c|c|c|c|c|}
\hline \multirow[t]{2}{*}{ Age of the Participants } & \multirow[t]{2}{*}{ Mean } & \multirow[t]{2}{*}{ Std. Error } & \multicolumn{2}{|c|}{ 95\% Confidence Interval } \\
\hline & & & Lower Bound & Upper Bound \\
\hline $8-10$ & $2.123^{\mathrm{a}}$ & .192 & 1.590 & 2.656 \\
\hline $10-12$ & 1.568 & .204 & 1.002 & 2.133 \\
\hline $12-14$ & 4.078 & .204 & 3.512 & 4.643 \\
\hline
\end{tabular}

The above table illustrates the range of mean result of population from lower bound to upper bound of $95 \%$ confidence intervals on the basis of age. For example, the range of value of confidence intervals would be from 1.59 to 2.65 of age 8-10, for age 10-12 would be from 1.00 to 2.133 and for the participants of age 12-14 would be from 3.51 to 4.6 before the instructions.

Table No. 15. Gender and Age of the Participants

\begin{tabular}{|c|c|c|c|c|c|}
\hline \multirow[t]{2}{*}{$\begin{array}{l}\text { Gender of } \\
\text { participants }\end{array}$} & $\begin{array}{l}\text { the Age of } \\
\text { participants }\end{array}$ & the Mean & $\begin{array}{l}\text { Std. } \\
\text { Error }\end{array}$ & \multicolumn{2}{|c|}{$\begin{array}{l}\text { 95\% Confidence Interval } \\
\text { Lower Bound Upper } \\
\text { Bound }\end{array}$} \\
\hline & $8-10$ & $\mathrm{a}$ & & & \\
\hline \multirow[t]{3}{*}{ Male } & $10-12$ & 1.660 & .332 & .737 & 2.583 \\
\hline & $12-14$ & 4.645 & .235 & 3.992 & 5.298 \\
\hline & $8-10$ & 2.123 & .192 & 1.590 & 2.656 \\
\hline \multirow[t]{2}{*}{ Female } & $10-12$ & 1.475 & .235 & .822 & 2.128 \\
\hline & $12-14$ & 3.510 & .332 & 2.587 & 4.433 \\
\hline
\end{tabular}

The above table describes the confidence intervals with the interaction of both factors. The first row of males, aged 8-10 comprised of dots which indicates that there were no male participants from the age of 8-10. The least low bound range is 3.99 and maximum value is 5.29 of male (age of 12-14) which highlights the confidence intervals (95\%), the mean result of the male group would be high, approximately from the range 3.99 to the 5.29 as compared to the female participants which is 2.58 to the 4.43 .

Two-way ANOVA also displayed a graph through which the level of gender and age of the participants with relation to the scores can be detected. Furthermore, the interaction between the subjects is also illustrated in the graph. 


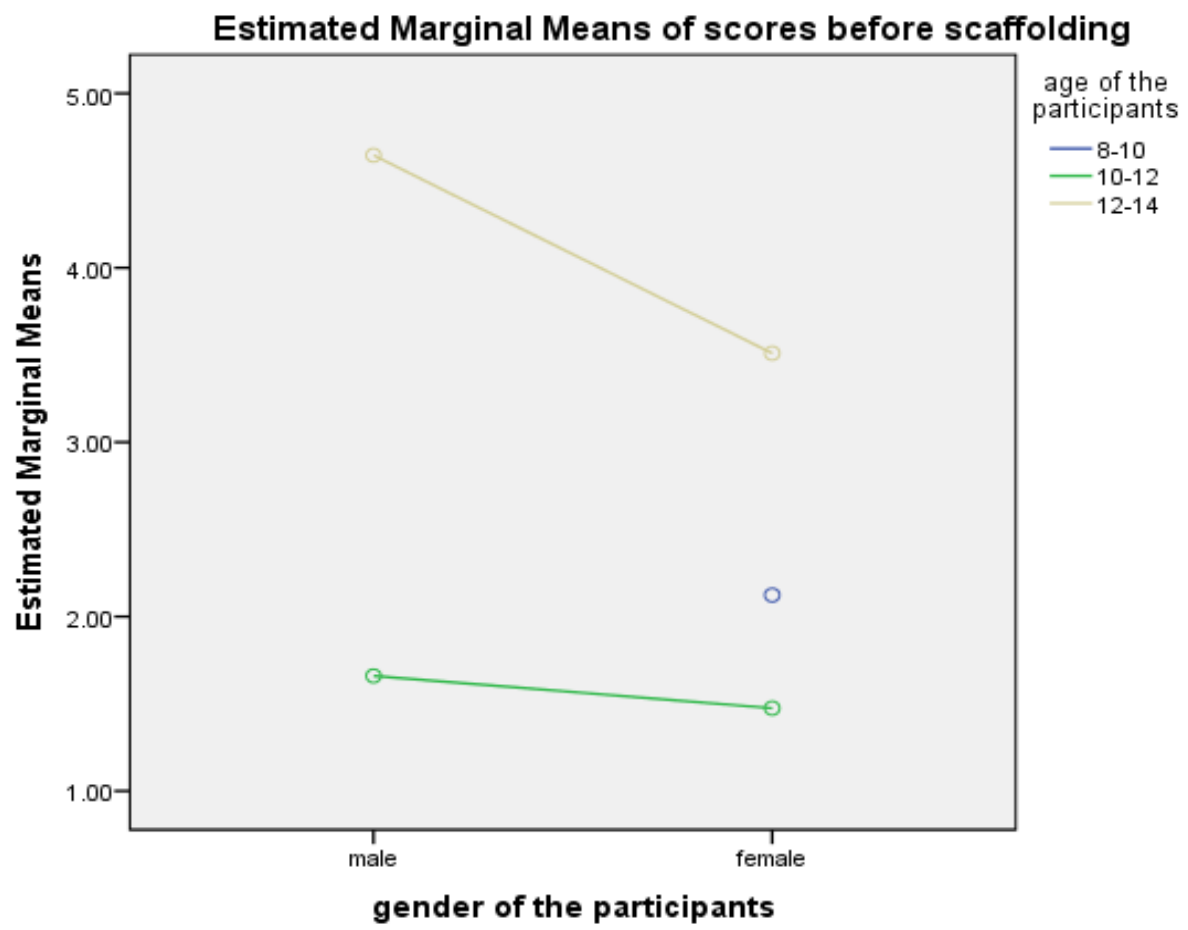

Non-estimable means are not plotted

Graph-1

In graph, there are three colors which indicate the mean estimation with age level of participants (blue for the age of 8-10, green for 10-12 and brown for the age of 12-14). Estimated margin is indicated on $y$-axis and gender on the x-axis. Graphical form of the result highlights the fact that the estimated mean of female group aged 10-12 is lower than the male group and same in the case of participants of ages 12-14. The blue dot is indicating that there are only females of age 810. Graph is also indicating that the mean result of first group of twins and singleton (age 8-10) is higher than the second group (age of 10-12). On the other hand, the mean result of third sample is greater than the other two in the pretest; test before scaffolding. The graph is also indicating that there is no interaction in both factors (age and gender) because the graph lines are parallel which means that there is no interaction between the factors before treatment.

Table No. 16. Descriptive Statistics

\begin{tabular}{ccccc}
\hline $\begin{array}{c}\text { Gender of the } \\
\text { participants }\end{array}$ & $\begin{array}{c}\text { Age of the } \\
\text { participants }\end{array}$ & Mean & Std. Deviation & N \\
\hline \multirow{3}{*}{ Male } & $10-12$ & 2.4000 & & 1 \\
& $12-14$ & 9.3450 & .38891 & 2 \\
& Total & 7.0300 & 4.01912 & 3 \\
& $8-10$ & 2.6200 & .29547 & 3 \\
Female & $10-12$ & 2.0050 & .41719 & 2 \\
& $12-14$ & 10.7000 &. & 1 \\
& Total & 3.7617 & 3.42260 & 6 \\
& $8-10$ & 2.6200 & .29547 & 3 \\
Total & $10-12$ & 2.1367 & .37287 & 3 \\
& $12-14$ & 9.7967 & .82924 & 3 \\
& Total & 4.8511 & 3.74569 & 9 \\
\hline
\end{tabular}

The above table describes the descriptive statistics of scores after scaffolding. It can be seen that the highest mean is 10.7 in the second column, which is of female age group 12-14 and in the 
case of male group the mean is likely 9.3 of age 12-14. The lowest mean is of the female of age 1012 which is 2.00. So, after scaffolding the mean of female group is higher than the male.

Table No. 17. Equality of Error Variances

\begin{tabular}{llll}
\hline F & df1 & df2 & Sig. \\
\hline 3.759 & 4 & 4 & .114 \\
\hline
\end{tabular}

a. Design: Intercept + gender + age + gender $*$ age

The Sig values of Leven's test of equality of error variances are not significantly different across the group. The Sig. value of Leven's test is 0.114 which is more than 0.05 which indicates that the null hypothesis that there is no difference in the achievement of twins and singletons on the bases of gender and age cannot be rejected.

Table No. 18. Subjects Effects

\begin{tabular}{lllllll}
\hline Source & $\begin{array}{l}\text { Type III Sum Df } \\
\text { of Squares }\end{array}$ & $\begin{array}{l}\text { Mean } \\
\text { Square }\end{array}$ & F & Sig. & $\begin{array}{l}\text { Partial Eta } \\
\text { Squared }\end{array}$ \\
\hline Corrected Model & $111.742^{\mathrm{a}}$ & 4 & 27.935 & 223.528 & .000 & .996 \\
Intercept & 204.265 & 1 & 204.265 & 1634.447 & .000 & .998 \\
Gender & .307 & 1 & .307 & 2.458 & .192 & .381 \\
Age & 90.120 & 2 & 45.060 & 360.550 & .000 & .994 \\
gender * age & 1.021 & 1 & 1.021 & 8.168 & .046 & .671 \\
Error & .500 & 4 & .125 & & & \\
Total & 324.041 & 9 & & & & \\
Corrected Total & 112.242 & 8 & & & & \\
\hline
\end{tabular}

a. R Squared $=.996$ (Adjusted R Squared $=.991)$

The above table shows the descriptive statistics of scores after scaffolding. In the first column, there is gender in the third row, there is Sig. value 0.192 which is greater than the $\alpha$ value which is 0.05. It illustrates that the null hypothesis, there is no effect of gender on the score's achievement of twins and singletons, is rejected. Secondly, the value of age is (0.00) which is less than $\alpha$ value, so the null hypothesis that there is no effect of age in the scores achievement after scaffolding, is accepted. Thirdly, the interaction between two factors (gender and age) can be seen by the Sig value which is about 0.04 and is less than 0.05 , so the null hypothesis that there is no interaction between the factors or there is no effect of sum of the factors on the achievement of scores after scaffolding is rejected.

After the descriptive statistics, there are also different tables that indicate the level of confidence intervals of scores after instructions or scaffolding.

Table No. 19. Gender of the Participants

\begin{tabular}{lccll}
\hline $\begin{array}{l}\text { Gender } \\
\text { Participants }\end{array}$ & of & the Mean & Std. Error & \multicolumn{2}{l}{$\begin{array}{l}\text { 95\% Confidence Interval } \\
\text { Lower Bound }\end{array}$} & Upper Bound \\
\hline Male & $5.873^{\mathrm{a}}$ & .216 & 5.271 & 6.474 \\
Female & 5.108 & .160 & 4.665 & 5.551 \\
\hline
\end{tabular}

The above table highlights the mean and confidence interval's range (from lower to higher) of participants after scaffolding on the basis of male and female groups. The mean of male group is approximately 5.87 and mean of female group is 5.108. The value of confidence interval indicates that the unknown parameter would be approximately among the range of 5.27 to 6.47 for males and for females, it is from 4.66 to 5.55 .

The following table shows the mean and confidence of interval of the participants after scaffolding with the perspective of age. The mean of participants of ages 8-10 is equal to 2.62 and range of unknown parameters varies maximally from 2.05 to 3.18 . The mean of participants of ages $10-12$ is equal to 2.20 and value of confidence interval is from 1.601 to 2.804 and for the participants of ages 12-14 is equal to 10.02 with confidence interval having a range of 9.421 to 10.62 . 
Table No. 20 Age of the Participants

\begin{tabular}{lllll}
\hline Age of the Participants Mean & Std. Error & \multicolumn{2}{c}{ 95\% Confidence Interval } \\
& & & Lower Bound & Upper Bound \\
\hline $8-10$ & $2.620^{\mathrm{a}}$ & .204 & 2.053 & 3.187 \\
$10-12$ & 2.202 & .216 & 1.601 & 2.804 \\
$12-14$ & 10.022 & .216 & 9.421 & 10.624 \\
\hline \multicolumn{2}{l}{} & \multicolumn{2}{l}{ The } &
\end{tabular}
participants after scaffer describes the effect of sum of both factors, including both age and gender. The dot (.) in the first row is showing the absence of males (aged 8-10).

Table No. 21 Gender and Age of the Participants

\begin{tabular}{llllll}
\hline $\begin{array}{l}\text { Gender of the } \\
\text { Participants }\end{array}$ & $\begin{array}{l}\text { Age of the } \\
\text { Participants }\end{array}$ & Mean & \multicolumn{2}{c}{$\begin{array}{c}\text { Std. Error 95\% Confidence Interval } \\
\text { Lower Bound Upper Bound }\end{array}$} \\
\hline \multirow{2}{*}{ Male } & $8-10$ &. &. & & \\
& $10-12$ & 2.400 & .354 & 1.418 & 3.382 \\
& $12-14$ & 9.345 & .250 & 8.651 & 10.039 \\
Female & $8-10$ & 2.620 & .204 & 2.053 & 3.187 \\
& $10-12$ & 2.005 & .250 & 1.311 & 2.699 \\
& $12-14$ & 10.700 & .354 & 9.718 & 11.682 \\
\hline
\end{tabular}

The plot of the results illustrates the link among the independent and dependent variables. Blue dot is non-estimated because in that sample, there are no male participants. The plot is highlighting the mean of the scores after scaffolding or after posttest. In this graph, the value of females with ages 10-12 is lower than the males'. On the other hand, the scores of the female participants of ages 12-14 are more than their male participants and the graph is indicating that the progress level of females is more than the males. Furthermore, the graph is highlighting that there is no interaction between factors after scaffolding also because graph lines are parallel to each other after treatment and they are not cross over each other.

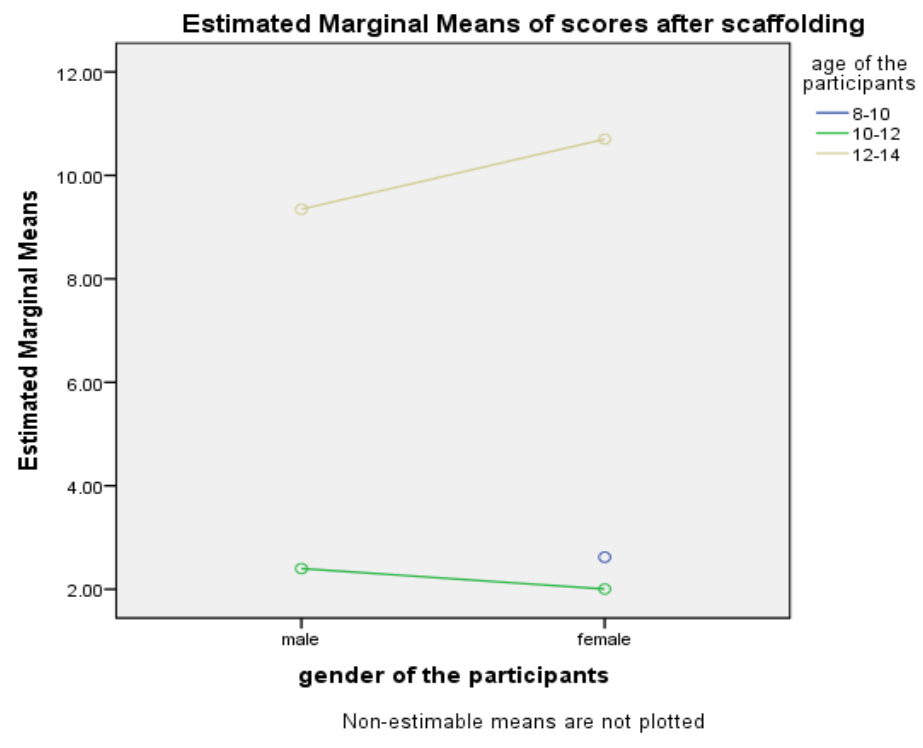

\section{Graph-2}

The findings show that there is no significant difference between the singles and twins is rejected and the alternative hypothesis; there is a significant difference between the twins' and singletons' learning scores and abilities is accepted. As it can also be seen that the researchers found the difference manually and then used SPSS independent test to examine either difference exists or not. The researchers applied the socio-cultural theory of Vygotsky while considering the two steps; ZPD and scaffolding. It was Vygotsky who has drawn the focus of researchers towards the learning 
of a child with scaffolding or with any supportive activity. The main purpose of this theory was to take pretest and posttest with scaffolding to highlight the difference of learning of twins versus singles. As the comparison across the monozygotic, dizygotic twin and non- twin siblings was explored by Fortuna, Goldner and knafo (2010) in which they hypnotized that same sex might have more dependence than the opposite sex.

\section{CONCLUSION}

According to the results of this research, it can be concluded that although there is an effect of genetics on twins learning but there is also effect of outer environment on the learning of the twins. Furthermore, it can be concluded that one of co-twins was affected more than the other in case of twins in each group. They were both under the same observation but their results are different. As Dale, Harlaar and Plomin (2012) claimed that there is effect of genetics on twins not internally but also externally through outcomes. So, what types of genetic factors affect psycholinguistics and cognition of the twins are not recognized yet.

Dale et al., (2012) recommended the further research about the twins and singletons difference on the level of SLA (second language acquisition) with respect to the social background, family attachment and school level studies. The researchers also found the reasons of difference in the learning of the twins and singletons. As the first question of the study is to find the difference between twins and singletons development at early school level, so the researchers used the method of zone of proximal development in the research. The researchers highlighted the difference in the pre-test and posttest of the participants manually and thoroughly while using SPSS.

As it is an experimental study the researchers added picture description, sentence making and reading skills in both pretest and post-test as Khaliliaqdam (2014) did in his research about ZPD (zone of proximal development). ZPD (zone of proximal development) demonstrated that for learning L1, there must be neighborhood, care takers, parents or any other person to guide the child. But in the case of L2 learning, there must be a context for the learning of second language with the tutor. Without proper environment of learning second language, it is difficult for learner to learn language. So, for L2 learners, a teacher is the best guide and helper. The entire observation of the researchers revealed that as the monozygotic twins always share $100 \%$ of their genetics but dizygotic twins share $50 \%$ of genetics as well as according to Vygotsky's theory of proximal one can learn from less or more capable peers. The researchers observed during the whole session that one of the co-twins was more active and one was less active in each case. As Lenneberg (1967) claimed that $90 \%$ of identical twins are considered having similar language development as compared to nonidentical twins. One more thing to be noted is that the researchers found that the less active co-twin got fewer scores than the more active co-twin as well as being less interested in academic activities but was more active in non-academic activities. Twin-ship has a great effect on the learners of L2.

Secondly, the present study deals with the question either twin-ship affects the learning of second language or not, in other words, the correlation between twin-ship and second language learning. The findings of observations exposed that ZPD always plays a vital role in the learning process. Scaffolding as a treatment before the posttest is a part of zone of proximal development. According to Gibbon's study (2002), there are some aspects of learning that a learner can learn 'alone' but there are some aspects of learning that the learner has to learn while imitating his elder or care takers to achieve the goal. Vygotsky's theory of zone of proximal development explained, it is not important that the helper or guide of the learner should be more capable. The learner can learn things and language especially from equal peers or from less capable person. The results also throw light on the point that there is a significant difference in the learning of second language of twins and singletons.

\section{REFERENCES}

Byrne, B., Samuelsson, S., Wadsworth, S., Hulslander, J., Corley, R., Defries, J. C., Quain, P., Willcutt, E. G., \& Olson, R. K. (2007). Longitudinal twin study of early literacy development: Preschool through grade 1. Reading and Writing: An Interdisciplinary Journal, 20(1-2), 77-102.

Day, E. J. (1932). The development of language in twin: A comparison of twins and single children. Child development, 3(3), 179-199. 
Dale, P. S., Harlaar, N., Haworth, C. M., \& Plomin, R. (2010). Two by two: A twin study of second language acquisition. Psychological Science, 21(5), 635-640.

Dale, P. S., Harlaar, N., \& Plomin, R (2012). Nature and Nurture in School Based Second Language Achievement. Language Learning, 62, 28-48.

Dennen, V. P., \& Burner, K. J. (2008). The cognitive apprenticeship model in educational practice. In Jonassen D., Spector M. J., Driscoll M., Merrill M. D., Merrienboer J. (Eds.), Handbook of research on educational communications and technology, (pp. 425-439). New York: Lawrence Erlbaum Associates, Taylor \& Francis Group.

Fortuna, K., Goldner, I., \& Knafo, A. (2010). Twin relationships: A comparison across monozygotic twins, dizygotic twins, and nontwin siblings in early childhood. Family Science, 1(3-4), 205211.

Garitte, C., Almodovar, J. P., Benjamin, E., \&Canhao, C. (2002). Speech in same-and different- sex twins 4 and 5 years old. Twin Research and Human Genetics, 5(6), 538-543.

Gibbons, P. (2002). Scaffolding language, scaffolding learning. Portsmouth, NH: Heinemann.

Harlaar, N., Hayiou-Thomas, M. E., Dale, P. S., \& Plomin, R. (2008). Why do preschool language abilities correlate with later reading? A twin study. Journal of Speech, Language, and Hearing Research, 51(3), 688-705.

Johnston, C., Prior, M. R., \& Hay, D. (1984). Prediction of reading disability in twin boys. Developmental Medicine \& Child Neurology, 26(5), 588-595.

Kozulin, A., Ageyev, V. S., Gindis, B., \& Miller, S. M. (Eds.). (2003). Vygotsky's educational theory in cultural context. Cambridge University Press.

Khaliliaqdam, S. (2014). ZPD, scaffolding and basic speech development in EFL context. ProcediaSocial and Behavioral Sciences, 98, 891-897.

Kozulin, A., Ageyev, V. S., Gindis, B., \& Miller, S. M. (Eds.). (2003). Vygotsky's educational theory in cultural context. Cambridge University Press.

Lenneberg, E. H. (1967). Biological Foundations of Language. New York, NY: John Wiley.

Mcmahon, S. A. N. D. R. A., \& Dodd, B. (1997). A comparison of the expressive communication skills of triplet, twin and singleton children. European Journal of Disorders of Communication, 32(3), 328-345.

Mariani, L. (1997). Teacher support and teacher challenge in promoting learner autonomy. Perspectives, a Journal of TESOL Italy, 23(2).

Rezaee, A. A., \& Azizi, Z. (2012). The Role of Zone of Proximal Development in the Students' Learning of English Adverbs. Journal of Language Teaching and Research, 3(1), 51.

Stevenson, J., Graham, P., Fredman, G., \& Mcloughli, V. (1987). A twin study of genetic influences on reading and spelling ability and disability. Journal of child psychology and psychiatry, 28(2), 229-247.

Thorpe, K. (2006). Twin children's language development. Early human development, 82(6), 387395.

Wood, D., Bruner, J., \& Ross, G. (1976). The role of tutoring in problem-solving. Journal of Child Psychology and Child Psychiatry, 17, 89-100.

Vygotsky, L. S. (1978). Mind in society. Cambridge, MA: MIT Press. 
APPENDIX-I

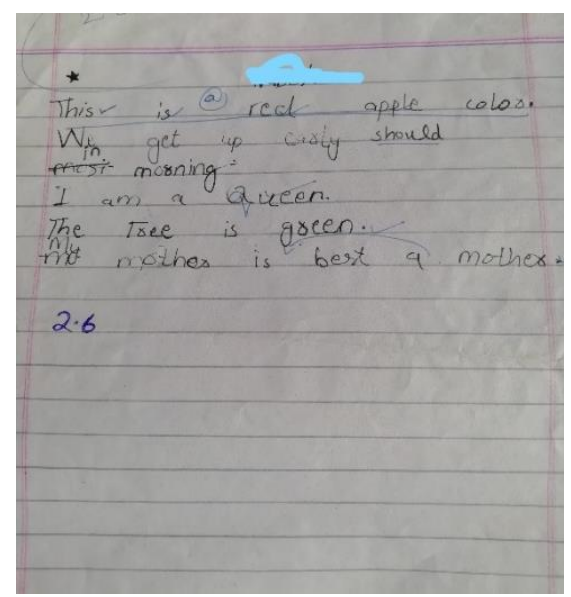

Fig. 2

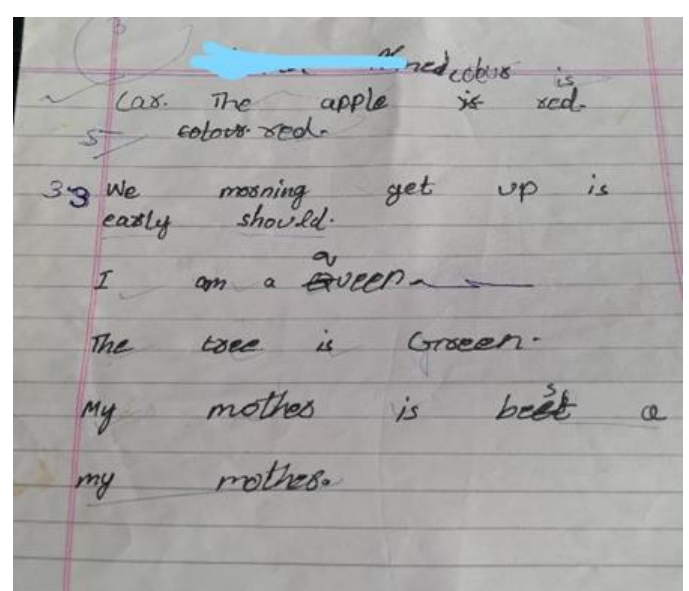

Fig. 3

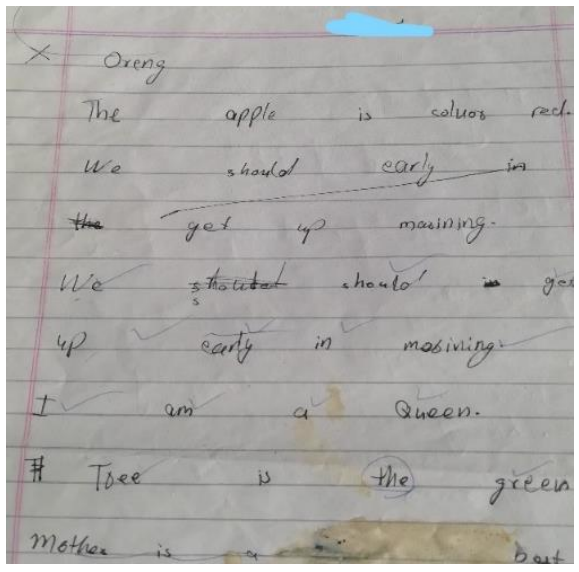

Fig. 4

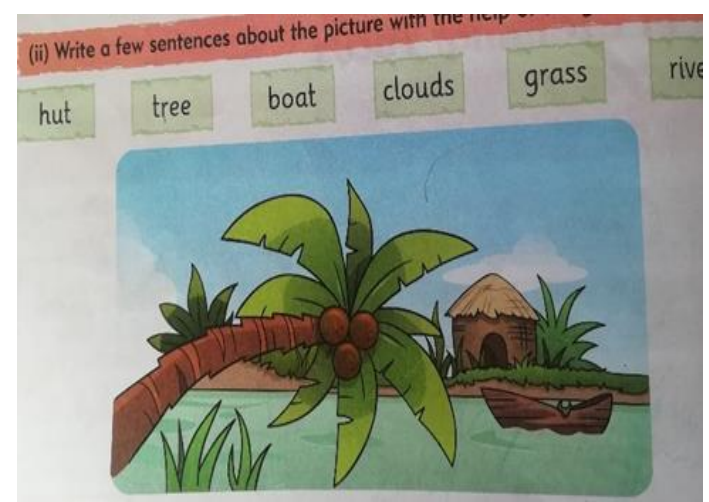

Fig. 5

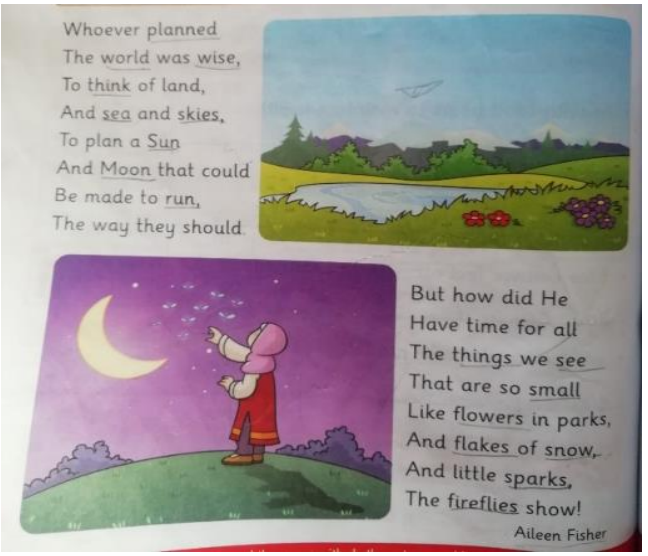

Fig. 6 


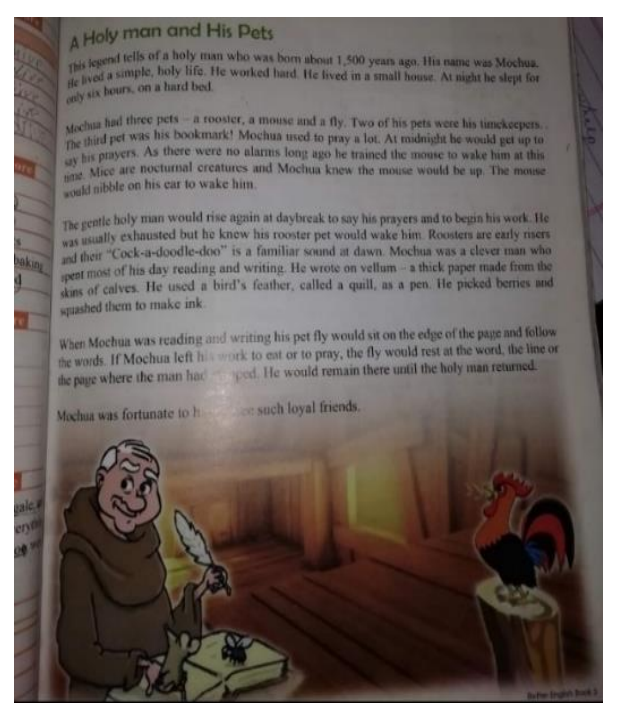

Fig. 7

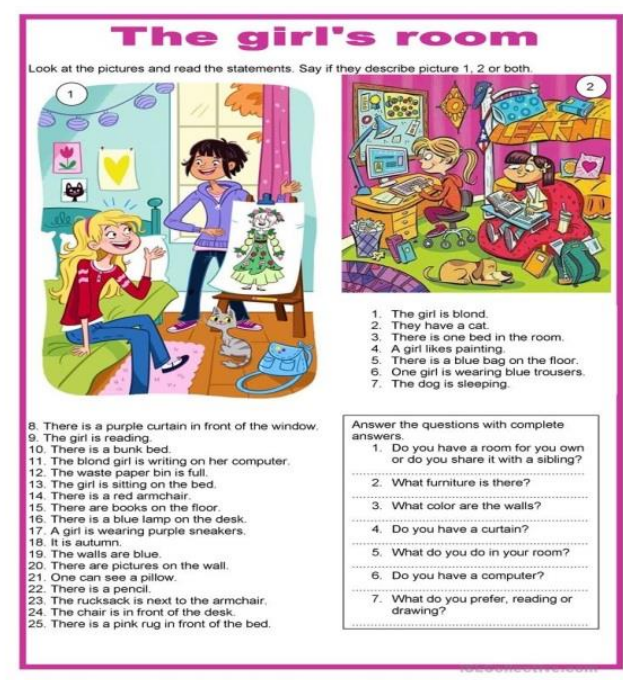

Fig. 8

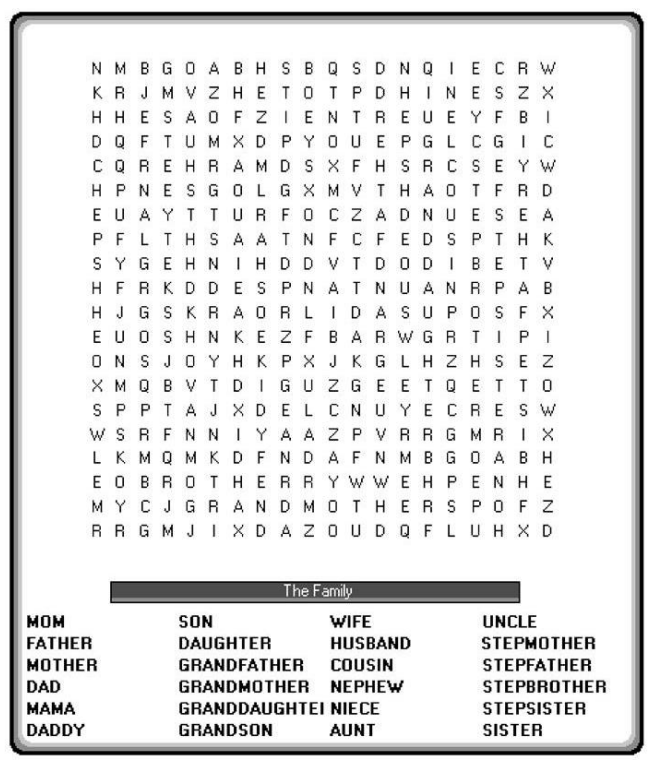

Fig. 9 


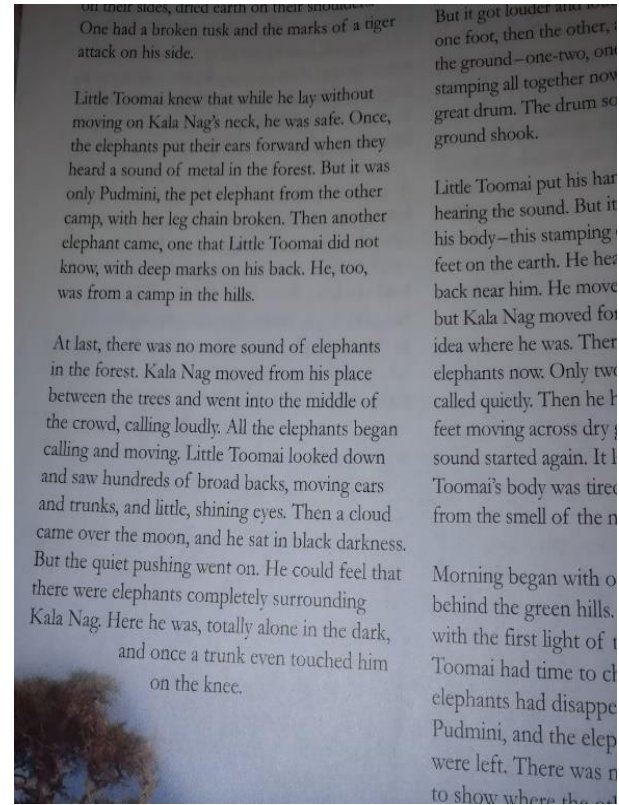

Fig. 10

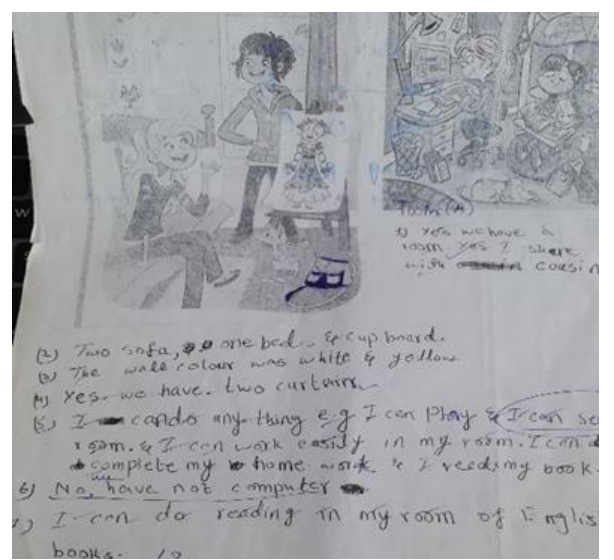

Fig. 12

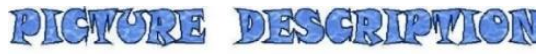
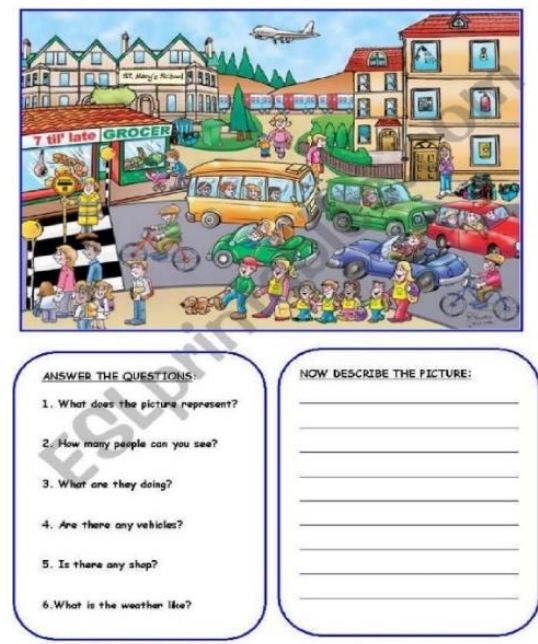

Fig. 11

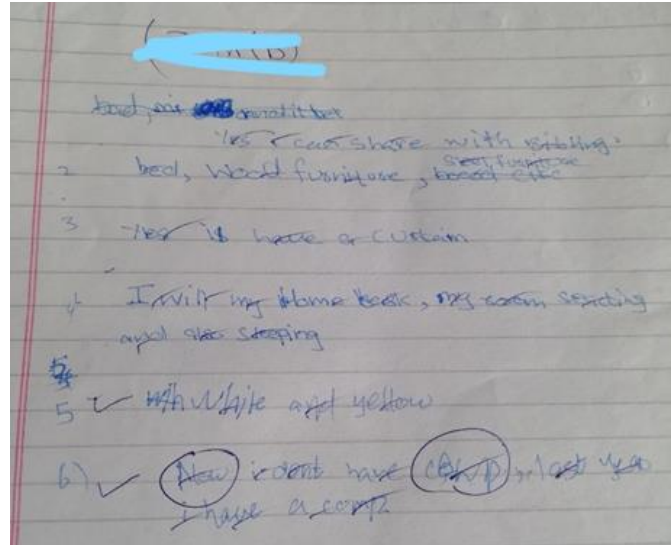

Fig. 13

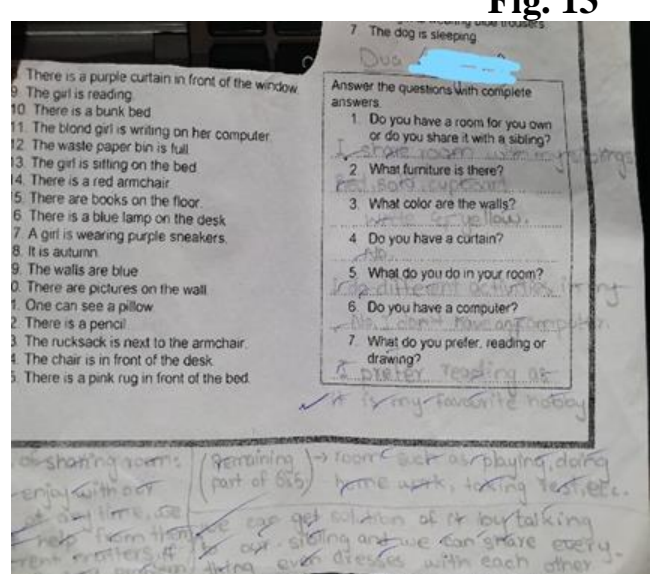

Fig. 14 